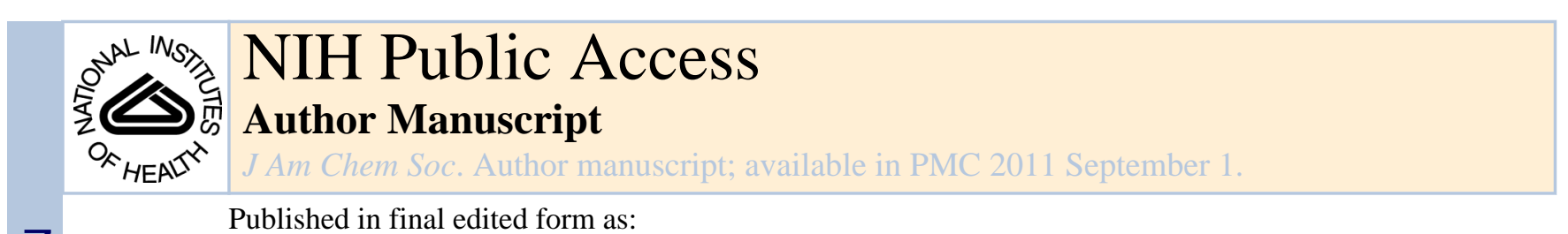

Published in final edited form as:

J Am Chem Soc. 2006 March 22; 128(11): 3543-3553. doi:10.1021/ja0525859.

\title{
Origins of Stereoselectivity in Diels-Alder Cycloadditions Catalyzed by Chiral Imidazolidinones
}

\author{
Ruth Gordillo and K. N. Houk \\ Department of Chemistry and Biochemistry, University of California, Los Angeles, CA \\ 90095-1569
}

\begin{abstract}
B3LYP/6-31G(d) density functional theory has been used to study Diels-Alder reactions of cyclopentadiene with $\alpha, \beta$-unsaturated aldehydes and ketones organocatalyzed by MacMillan's chiral imidazolidinones. Preferred conformations of transition structures and reaction intermediates have been located. The dramatically different reactivities and enantioselectivities exhibited by two similar chiral imidazolidinones are rationalized.
\end{abstract}

\section{Introduction}

The introduction of specific chirality into synthetic targets using metal-free chiral organocatalysts has become a field of great interest in recent years. ${ }^{1}$ In 2000, MacMillan and coworkers reported the first highly enantioselective Diels-Alder reaction of cyclopentadiene with $\alpha, \beta$-unsaturated aldehydes catalyzed by the chiral imidazolidinone $\mathbf{1}$, derived from phenylalanine (eq 1). The authors demonstrated that the reaction of a variety of aldehydes ( $R$ $=\mathrm{Me}, \mathrm{Pr}, i$-Pr, Ph, furyl) occurs with good yield and enantioselectivity ( $>75 \%$ yield, endo $>90 \%$ ee, exo $>84 \%$ ee). ${ }^{2}$

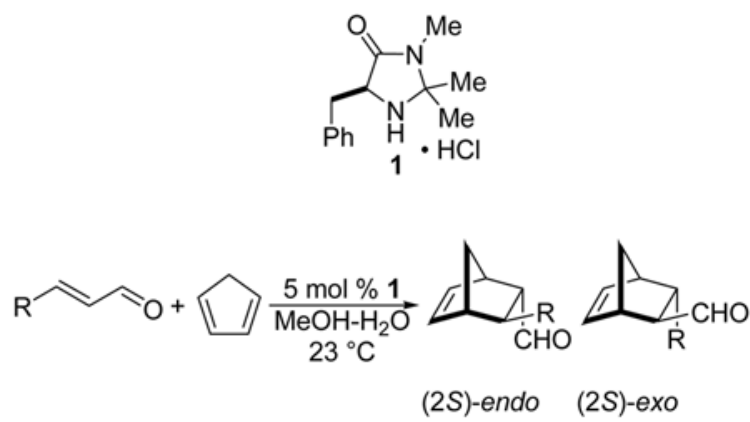

Catalyst 1 was also successful for 1,3-dipolar cycloaddition reactions between nitrones and and $\alpha, \beta$-unsaturated aldehydes, ${ }^{3}$ alkylation reactions of pyrroles by olefinic aldehydes, ${ }^{4}$ and $\alpha$-chlorination of aldehydes. ${ }^{5}$

houk@chem.ucla.edu.

Supporting Information Available: Complete references 18 and 21, Cartesian coordinates of all reported structures, as well as the total electronic and zero-point vibrational energies. This material is available free of charge via the Internet at http://pubs.acs.org. 
For asymmetric alkylations of indoles, enantioselectivities were improved by using the 2-tbutyl imidazolidinone $2 .{ }^{6}$ Compound $\mathbf{2}$ gave also excellent results as enantioselective organocatalyst in 1,4-addition reactions of electron-rich benzenes to $\alpha, \beta$-unsaturated aldehydes, ${ }^{7}$ in the synthesis of butenolides by Mukaiyama-Michael with silyloxyfurans. ${ }^{8}$

In 2004, MacMillan et al. reported the enantioselective synthesis of (-)-flustramine B, using 6-bromotryptamine and acrolein as starting materials, and compound $\mathbf{2}$ as organocatalyst, by a cascade addition-cyclization strategy (Scheme 1). ${ }^{9}$

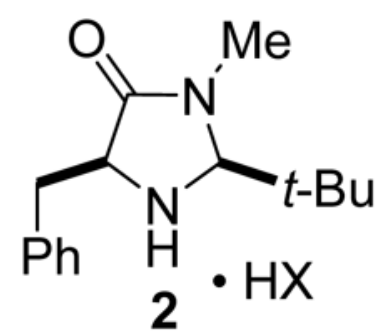

More recently, the same research group used imidazolidinone $\mathbf{2}$ for aldehyde-aldehyde aldol reactions obtaining as major compound the enantiomer of the most favored product in the proline catalyzed process. ${ }^{10}$ List and coworkers have also obtained good yields and enantioselectivities in asymmetric hydrogenations of $\alpha, \beta$-unsaturated aldehydes using amine 2 as organocatalyst. ${ }^{11}$

One important factor that determines efficiency of imidazolidinone catalysts in their asymmetric enantioselective reactions is the reversible formation of iminium ions from chiral imidazolidinones and $\alpha, \beta$-unsaturated carbonyl compounds. Hydrolysis to the final products generally occurs smoothly, and does not have any influence in the chiral center generated in the previous step of the reaction (Scheme 2).

Surprisingly, catalysts $\mathbf{1}$ and $\mathbf{2}$ were found to be unsuccessful in the Diels-Alder cycloaddition reactions of cyclopentadiene with 4-hexen-3-one ( $<30 \%$ yield, $0 \%$ ee). Higher reaction rates and moderate enantioselectivity could be obtained by using the cis-2,5diphenylamine 3 (88\% yield, 21:1 endo:exo, $47 \%$ ee). Introduction of a benzyl group at C2 of the imidazolidinone ring (catalyst 4 ) provided a higher enantioselectivity (83\% yield, 23:1 endo:exo, $82 \%$ ee). The best results were obtained with amine 5 which possesses a 5methyl-2-furyl group at $\mathrm{C} 2$ (89\% yield, $25: 1$ endo:exo, $90 \%$ ee). ${ }^{12}$<smiles>CN1C(=O)C(c2ccccc2)NC1c1ccccc1</smiles>

$3^{\cdot} \cdot \mathrm{HClO}_{4}$<smiles>CN1C(=O)C(Cc2ccccc2)NC1c1ccccc1</smiles>

$4 \cdot \mathrm{HClO}_{4}$<smiles>COc1ccc(C2NC(Cc3ccccc3)C(=O)N2C)o1</smiles>

MacMillan et al. explained the enantioselectivities according to a model of the iminium ion 6 calculated with MM3, depicted in Figure 1. ${ }^{12,13}$ The trans-iminium isomer 6 will be energetically disfavored on the basis of nonbonding interactions between the benzyl and $\mathrm{CH}_{2} \bullet$ (green) substituents, and the calculated cis-iminium isomer $\mathbf{6}$ will be selectively exposed to cycloaddition at the $\mathrm{Si}$-face.

In this paper we present a detailed theoretical study of the Diels-Alder cycloaddition reactions of cyclopentadiene with $(E)$-crotonaldehyde and 4-hexen-3-one catalyzed by chiral 
imidazolidinones $\mathbf{1}$ and $\mathbf{5}$ in order to explain the differences observed in reaction rates and enantioselectivities.

Our research group have demonstrated that hybrid density functional theory ${ }^{14}$ can be a powerful tool to predict enantioselectivities in asymmetric organocatalyzed reactions. ${ }^{15-17}$ In a previous work the theoretical study of enantioselective alkylation reactions of pyrroles and indoles organocatalyzed chiral imidazolidinones have been reported. ${ }^{16}$ In this article, the authors rationalized theoretically the structural factors that govern the different observed enantioselectivities when either catalyst $\mathbf{1}$ or $\mathbf{2}$ was employed.

With the aim to determine quantitatively the catalytic effect produced by secondary amines as organocatalysts, the transition structures corresponding to the uncatalyzed Diels-Alder reactions between cyclopentadiene with $\alpha, \beta$-unsaturated aldehydes and ketones have been also computed.

\section{Computational Methods}

All structures were computed using the functional B3LYP $\mathrm{P}^{14 \mathrm{a}-\mathrm{c}}$ and the $6-31 \mathrm{G}(\mathrm{d})^{14 \mathrm{~d}-\mathrm{f}}$ basis sets as implemented in Gaussian $98 .{ }^{18}$ All energy minima and transition structures were characterized by frequency analysis. Reported gas phase energies are electronic energies plus zero point vibrational energy corrections, scaled by $0.9806 .{ }^{19}$ The energies computed for structures in solvent (water $\varepsilon=78.39$, benzene $\varepsilon=2.247$ ) include the electronic energy at the B3LYP/6-31G(d) level of theory plus the solvation energy calculated with the CPCM solvation model ${ }^{20}$ as implemented in Gaussian $03^{21}$ at the $\mathrm{HF} / 6-31 \mathrm{G}(\mathrm{d}) / / \mathrm{B} 3 \mathrm{LYP} / 6-31 \mathrm{G}(\mathrm{d})$ level of theory, with the UAKS cavity model model. Both the electrostatic and non electrostatic components of the energy have been considered. Solvation energies of a representative group of neutral, anionic, and cationic molecules, are computed relatively well with this methodology. ${ }^{22}$

\section{Results and Discussion}

\section{Uncatalyzed Diels-Alder Reactions with $\alpha, \beta$-unsaturated aldehydes and ketones}

Figure 2 shows the $s$-trans- and $s$-cis- $(E)$-crotonaldehyde conformers, and their corresponding endo and exo transition structures. The $\boldsymbol{s}$-trans conformer of $\mathbf{7}$ is more stable than $s$-cis isomer by $1.4 \mathrm{kcal} / \mathrm{mol}$. All the calculated transition structures correspond to an asynchronous (carbon-carbon bond forming distance differences between 0.2 and $0.6 \AA$ ), but concerted, pathway. A 1:3.8 endo:exo ratio is predicted for the gas phase at $0{ }^{\circ} \mathrm{C}$. Previous studies of the Diels-Alder reaction of cyclopentadiene with methyl vinyl ketone predicted an 1.2:1 endo:exo ratio in the gas phase, and 3.7:1 in nitromethane at $0{ }^{\circ} \mathrm{C} .{ }^{23}$ According to preceding experimental results, in most of the cases an endo orientation of the carbonyl group is preferred, and this preference increases in polar solvents. ${ }^{23-25}$ In water the endo selectivity enhancement is accompanied by a considerable reaction acceleration due to enforced hydrophobic interactions between diene and dienophile. ${ }^{28-31}$ The introduction of an alkyl group at $\mathrm{R}_{2}$ slightly decreases the endo selectivity, ${ }^{26}$ while an inversion of the endo orientation is observed when the hydrogen atom at $R_{3}$ is substituted by an alkyl group. ${ }^{26,27}$ The results were attributed to an attractive $\mathrm{C}-\mathrm{H} \cdots \pi$ interaction between the methyl group and the diene $\pi$-system. ${ }^{26,35}$ 


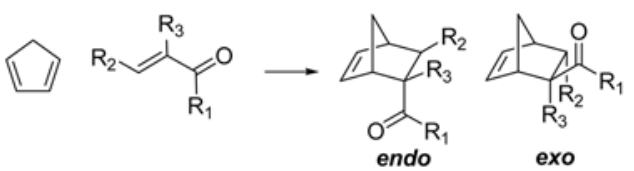

TS7 s-cis-exo is the most stable transition structure in the gas phase and benzene. A weak $\mathrm{CH} \cdots \mathrm{O}$ hydrogen bond involving the carbonyl oxygen of the dienophile and one of the hydrogen atoms of the $\mathrm{CH}_{2}$ group at the diene is likely a contribution (Figure 2). A partial negative charge of $0.48 \mathrm{u}$. a. is present at the carbonyl oxygen while there is a partial positive charge of 0.06 u.a. at Ha in the cyclopentadiene fragment (CHelpG charges). ${ }^{32}$ Both $s$-cis and $s$-trans-endo approaching are lower in energy than their corresponding exo transition structures, most likely due to the extisting $\mathrm{C}-\mathrm{H} \cdots \pi$ stabilizing interaction between the methyl group of the dienophile and the diene $\pi$-system in TS7 $s$-cis-exo and TS7 $s$-transexo. Increasing solvent polarity weakens these $\mathrm{CH} \cdots \mathrm{O}$ interactions. ${ }^{33,34}$ Single point calculations performed with the CPCM solvation model gave an endo:exo ratio of 1:2.4 in benzene for the reaction of 7 with cyclopentadiene at $0{ }^{\circ} \mathrm{C}$, that is, the exo preference decreases with respect to the same reaction in the gas phase. In water, a selectivity reversal occurs, and the calculated endo:exo ratio is 1.2:1.

Figure 3 displays the most stable 4-hexen-3-one conformer $(\mathbf{8})$ and transition structure for the Diels-Alder reaction (TS8 $s$-cis-exo) in the gas phase and in water. Conformer $\mathbf{8} s$-cis is more stable than the $s$-trans isomer by $1.1 \mathrm{kcal} / \mathrm{mol}$. The analysis of the calculated transition structures corresponding to the Diels-Alder reaction with cyclopentadiene in the gas phase gave similar results (see Supporting Information). The most stable transition state is TS8 $s$ cis-exo. The calculated endo:exo ratio at $0{ }^{\circ} \mathrm{C}$ in the gas phase was $1: 4.5$, slightly higher than predicted in the reaction of cyclopentadiene with $(E)$-crotonaldehyde. As a consequence of the steric hindrance by the ethyl group, TS8 $s$-cis-exo is also the most stable transition state in water, but the calculated endo:exo ratio decreases to 1:3.7. B3LYP/ $6-31 \mathrm{G}(\mathrm{d})$ overestimates the existing $\mathrm{C}-\mathrm{H} \cdots \mathrm{O}$ and $\mathrm{C}-\mathrm{H} \cdots \pi$ stabilizing interactions in the $s$-cisexo approaches. ${ }^{14,26,35}$

\section{Amine catalyzed Diels-Alder reactions with $\alpha, \beta$-unsaturated aldehydes and ketones}

The $s$-trans iminium formed from butenal and dimethylamine (9s-trans) is more stable than $9 s$-cis by $6.4 \mathrm{kcal} / \mathrm{mol}$ (Figure 4). ${ }^{16}$ Only the $s$-trans conformer was considered in the transition structure searching. The calculated endo- and exo- transition structures, shown in Figure 4, are concerted but very asynchronous. The carbon-carbon bond forming distances difference by $\sim 1 \AA$. Electronic activation energies are lower than in the case of the uncatalyzed cycloaddition by about $13 \mathrm{kcal} / \mathrm{mol}$ (Figure 2). The predicted endo:exo ratio was $1: 2$ in the gas phase at $0{ }^{\circ} \mathrm{C}$. In water the endo:exo ratio changes to 1:3.6.

Consistent with previous reported results, both s-trans-endo and exo transtition geometries for the reaction between $9 s$-trans cyclopentadiene performing a full optimization using the CPCM solvation model at the B3LYP/6-31G(d) level of theory and employing the UAKS cavity model, are very close to that corresponding to the gas phase, and slightly more synchronous (Figure 4). The relative energy difference is calculated to be $0.6 \mathrm{kcal} / \mathrm{mol}$ very close to the $0.7 \mathrm{kcal} / \mathrm{mol}$ obtained using CPCM single point calculations. ${ }^{22,36}$

Structures TS9 are similar to the most stable closed transition states located for the alkylation reaction of pyrrole with $(E)$-crotonaldehyde organocatalyzed by dimethylamine. ${ }^{16}$ However, transition vector motion along the reaction coordinate of TS9 corresponds to a 
concerted asynchronous Diels-Alder cycloaddition reaction. ${ }^{37}$ In addition, no intermediate corresponding to a stepwise process could be found after perfoming intrinsic reaction coordinate (IRC) calculations in the gas phase and in water. The calculated transition structures TS9 optimize to the corresponding cycloadducts. Our results are in excellent agreement with previous results reported by Domingo related to the reaction between $N, N$ dimethyleneamonium cation and cyclopentadiene. ${ }^{36 \mathrm{c}}$ The author concluded that the reaction takes place as a highly asynchronous concerted process with a large polar character and the process can be characterized by the nucleophilic attack of cyclopentadiene to the electronpoor cation. The transition states show a Michael-type addition character with a concomitant cyclization without formation of any zwitterionic intermediate.

One can explain the observed experimental data for the Diels-Alder cycloaddition of cyclopentadiene with $\alpha, \beta$-unsaturated aldehydes organocatalyzed by imidazolidinones using our previous results on the theoretical study of alkylation reactions of pyrrole organocatalyzed by imidazolidinones $\mathbf{1}$ and $\mathbf{2}^{2,16}$ The small energy differences found between the endo and exo orientations of each conformer demonstrated that a distinct preference for one over the other does not occur. This fact is in agreement with the experimentally observed 1:1 endo:exo ratio (predicted endo:exo ratio is 1:1.5 for catalyst 1 and 1.3:1 for catalyst 2 in the gas phase at $25^{\circ} \mathrm{C}$ in the case of the alkylation reaction of $N$ methyl pyrrole with $(E)$-crotonaldehyde). A theoretical ee value of $70 \%$ for the endo product, and an ee value of $46 \%$ for the exo cycloadduct were obtained. This results are also in agreement with the higher enantioselectivity experimentally observed for the endo product (endo $90 \%$ ee, exo $86 \%$ ee). ${ }^{2}$

In 2002 Zora reported the AM1 theoretical study of the cycloaddition reaction of cyclopentadiene with allylidenammonium cation. ${ }^{38} \mathrm{~A}$ stepwise pathway was found, and the activation barrier for the cycloaddition to the $\mathrm{C}=\mathrm{C}$ bond was $4.2 \mathrm{kcal} / \mathrm{mol}$ lower than that to the $\mathrm{C}=\mathrm{N}$ bond.

Figure 5 displays the calculated $s$-trans and $s$-cis $N$-2-butenylidene- $N$-1-ethyl- $N$ methylmethanaminium cations (10). The relative energy differences between the $\mathbf{1 0} s$-trans iminium intermediate and the three located $\mathbf{1 0} s$-cis1-3 conformers are lower than in the case of $N$-2-butenylidene- $N$-methylmethanaminium cations (9) $(3.5,2.9$, and $3.8 \mathrm{kcal} / \mathrm{mol}$ respectively). This fact can be attributed to the presence of the ethyl group which generates steric hindrance in both $s$-cis and $s$-trans isomers. Only the $s$-trans conformer was considered in the transition structure searching.

Figure 6 shows the four calculated transition structures for the Diels-Alder reaction of $\mathbf{1 0} s$ trans and cyclopentadiene. The carbon-carbon bond forming distances are very similar to the $(E)$-crotonaldehyde case. The calculated endo:exo ratio was 3.1:1 in the gas phase at 0 ${ }^{\circ} \mathrm{C}$ due to steric hindrance between the methylene group in the cyclopentadiene ring and the ethyl group in the ketone fragment. In water, the calculated endo:exo ratio increases to 4.1:1. The most stable transition state was TS10a s-trans-endo. Endo and exo transition structures TS10a, in which the methyl group of the ethyl moiety is pointing away from the cyclopentadiene fragment, are more stable than TS10b structures by 2.6 and $1.6 \mathrm{kcal} / \mathrm{mol}$ respectively. Only transition structures analogous to TS10a were considered in further transition structure searching involving a larger number of atoms. Activation energies for $\mathbf{1 0}$ are about $11 \mathrm{kcal} / \mathrm{mol}$ lower than for $\mathbf{8}$ (Figure 3).

MacMillan performed the reaction in aqueous media and in the presence of $\mathrm{HClO}_{4}$ (one equivalent with respect to the amine catalyst, $20 \mathrm{~mol} \%$ with respect to ketone 8 ).${ }^{10}$ The computations were performed for the reaction involving protonated 4-hexen-3-one, and the results for the lowest energy path are shown in Figure 7. The isomeric reactants complexes, 
and transition states are given in the supporting information. The $s$-cis protonated species forms with cyclopentadiene an ion-molecule complex in the gas phase, and the activation barrier from this complex is only $3 \mathrm{kcal} / \mathrm{mol}$, even lower than the activation barrier for the iminium case. However, the formation of the protonated ketone from the protonated amine catalyst will be highly endothermic and little protonated ketone will be formed. The energies of formation of compound $\mathbf{1 1} s$-cis from $\mathbf{8} s$-cis and protonated form of amines $\mathbf{1}$ and $\mathbf{5}$ were calculated to be 17.4 and $18.1 \mathrm{kcal} / \mathrm{mol}$ respectively in the gas phase. The calculated transition structures are very asynchronous (carbon bond forming distance differences $\sim 1$ $\AA$ ), similarly to dimethylamine catalyzed cycloadditions. These results predicted an endo:exo ratio of $2.8: 1$ in the gas phase at $0{ }^{\circ} \mathrm{C}$. In water the calculated endo:exo ratio was 7.5:1 the same value found in the experiment for the reaction catalyzed by imidazolidinone 1. ${ }^{10}$

\section{Imidazolidinone catalyzed Diels-Alder cycloadditions}

Iminium ion intermediates-A complete conformational study of iminium complexes formed from $(E)$-crotonaldehyde and the chiral imidazolidinone $\mathbf{1}$ has been recently reported. ${ }^{15 f, 16}$ Contrary to previous force field energy minimizations, conformer $(\boldsymbol{E})-\mathbf{1 2 a},{ }^{2,39}$ which includes a stabilizing C-H $\cdots \pi$ interaction between one of the methyl groups at position $\mathrm{C} 2$ of the imidazolidinone ring, and the phenyl ring of the benzyl group at position $\mathrm{C} 5$, was found to be the global minimum. ${ }^{40}$ A number of conformers of similar energy were located; attack from the bottom, away from the benzyl group is favored as noted by MacMillan. $2,4,6,16$

Figures 9 and 10 show the twelve different conformers found in the case of imidazolidinone 1 and 4-hexen-3-one. These correspond to the $(E)$ and $(Z)$ configurations about the $\mathrm{N}^{+}=\mathrm{C}$ bond, the three staggered conformations involving the bond to the benzyl group, and two conformations of the ethyl group attached to the carbon-nitrogen double bond.

As in previous studies on the iminium complexes formed from imidazolidinone $\mathbf{1}$ and $(E)$ crotonaldehyde, ${ }^{16}$ the most stable conformer $(\mathbf{1 3}(\boldsymbol{E})$-a2 $)$ includes a stabilizing $\mathrm{C}-\mathrm{H} \cdots \pi$ interaction between one of the methyl groups at the phenyl ring of the benzyl group at position C5. ${ }^{38}$ The ethyl conformer $\mathbf{1 3}(\boldsymbol{E})$-a1 and $Z$-isomer $\mathbf{1 3}(\boldsymbol{Z})$-a2 are only 0.1 and 0.2 $\mathrm{kcal} / \mathrm{mol}$ higher in energy, respectively these three conformers constitute the $70 \%$ of all the species in the gas phase at $0{ }^{\circ} \mathrm{C}$ (Figures 9 and 10). The conformers commonly drawn by MacMillan et al. (b1 and b2) are $0.6-3.3 \mathrm{kcal} / \mathrm{mol}$ higher in energy and constitute $12 \%$ of the equilibrium mixture. The least stable structures correspond to $\mathbf{1 3}(Z)$-b1 and $\mathbf{1 3}(Z)$-c1 iminium intermediates due to strong steric repulsions between the ethyl group attached to the iminium carbon and the benzyl group at position $\mathrm{C} 5$ of the imidazolidinone ring.

In the case of imidazolidinone $\mathbf{5}$, the derived iminium ions have even more isomers because of rotation and isomerism around C2-furyl bond. A total number of 26 different conformers were located. The 4 most stable calculated iminium intermediates are shown in Figure 11. The " $\alpha$ " means that $\mathrm{H} 2-2-\mathrm{C}^{\prime}-\mathrm{O}$ ' dihedral angle is close to $180^{\circ}$.

The most stable $\mathbf{1 4}(E)$-b2 $\alpha$ structure is like that reported by MacMillan and coworkers based on a MM3 conformational search. ${ }^{12}$ Surprisingly, the $\mathbf{1 4}(Z)$-b2 $\alpha$ isomer is only $0.2 \mathrm{kcal} / \mathrm{mol}$ higher in energy. A large number of species will exist in the gas phase at $0{ }^{\circ} \mathrm{C}$, and a total of 26 different conformers could be located (see Supporting Information). Conformers 14(E)b2 $\alpha, \mathbf{1 4}(E)$-c2 $\alpha$ and $\mathbf{1 4}(Z)-\mathbf{b 2} \alpha$ are predicted to constitute $64 \%$ of all of them (Figure 11). This percentage is slightly lower than in the case of iminium intermediates $\mathbf{1 3}$.

Transition structure searching-For transition structure searching involving catalyzed reactions of 4-hexen-3-one with cyclopentadiene, the most stable iminium intermediates, 13 
and 14, were considered. The lowest energy calculated transition states involving iminium ions $\mathbf{1 3}$ and $\mathbf{1 4}$ are depicted in Figures 12 and 13, respectively (" $\delta$ " means a H2-C2-C1'-O' dihedral angle of about $-30^{\circ}$ ). Tables 1 and 2 list the relative energy differences, activation energies (calculated as the difference between the electronic energies of the transition structures and the sum of the electronic energies of cyclopentadiene and the corresponding iminium intermediate) and percentage of transition structures, TS13 and TS14, in the gas phase at $0{ }^{\circ} \mathrm{C}$.

All the transition structures are concerted but very asynchronous, and very similar to that previously calculated for the dimethylamine organocatalyzed reaction shown in Figure 5. In the gas phase, the lowest energy transition state related to imidazolidinone $\mathbf{1}$ catalyzed reaction (TS13 $(\boldsymbol{E})$-a1-endo) corresponds to the endo approach of the cyclopentadiene ring to the $S i, R e$ face (bottom face) of the most stable iminium ion conformer $13(\boldsymbol{E})$-a1; this approach accounts for $35 \%$ of all the transition structures. In water, the most stable transition structure is $\operatorname{TS13}(Z)$-a2-endo, corresponding to cyclopentadiene attack on the Si, Re face (top face) of $\mathbf{1 3}(\boldsymbol{Z})$-a2 conformer. TS13 (Z)-a2-endo accounts for more than $96 \%$ of all the transition structures in water at $0{ }^{\circ} \mathrm{C}$. In both cases, gas phase and water, the most stable calculated transition structures lead to the endo-enantiomer that is isolated as the major product of reaction. In the case of imidazolidinone $\mathbf{5}$, the lowest energy transition structure in the gas phase corresponds to the endo approach of the diene on the $S i, R e$ face (top face) of $\mathbf{1 4}(Z)-\mathbf{b} 2 \boldsymbol{\alpha}$ isomer. TS14 (Z)-b2a-endo accounts for only $35 \%$ of all the transition structures while the most stable calculated transition state in water, TS14 $(E)$-b1aendo, accounts for $80 \%$. As in the case of the calculations on amine $\mathbf{1}$ catalyzed reactions the lowest energy transition structures in both gas phase and water predict the product isolated as the major compound. The average calculated electronic activation energies are very similar for both $\mathbf{1}$ and $\mathbf{5}$ organocatalysis (13.4 and $13.1 \mathrm{kcal} / \mathrm{mol}$, respectively in the gas phase).

The Boltzmann distribution analysis predicted an endo:exo ratio of 6:1 and a theoretical ee value $>99 \%$ for the cycloaddition reaction catalyzed by $\mathbf{1}$ in the gas phase at $0{ }^{\circ} \mathrm{C}$. MacMillan and coworkers reported an endo:exo product ratio of 7:1 and 0\% ee for the same reaction performed in water at $0{ }^{\circ} \mathrm{C}$. Surprisingly, catalyst 5 which showed a remarkably improved endo- and enantioselectivities (25:1 endo:exo ratio and 99\% ee) gave an endo:exo ratio of 6:1 and a theoretical $70 \%$ ee value. ${ }^{12}$ The energies of all the transition structures in water with the CPCM solvation model at the HF/6-31G(d)//B3LYP/6-31G(d) level of theory and, with the UAKS cavity model have been also computed (see computational methods section). ${ }^{22}$ Solvation energies increase both endo selectivity and enantioselectivity. For catalyst 1, an almost 100\% endo selectivity was predicted, and in the case of amine 5 a 35:1 endo:exo ratio was calculated, versus the 25:1 experimental product ratio. Both catalysts are predicted to give $>99 \%$ ee, whereas experiments give $0 \%$ and $90 \%$ for catalysts $\mathbf{1}$ and $\mathbf{5}$ respectively. ${ }^{12}$

The possibility that one or both of these reactions could be reversible was also considered. The relative stabilities of the Diels-Alder cycloadducts obtained from the most stable calculated transition structures, TS13 (E)-a1-endo and TS14 (Z)-b2a-endo (Figure 14). The potential-energy profiles show that the amine 5 catalyzed reaction is only $1.0 \mathrm{kcal} / \mathrm{mol}$ more exothermic than the amine $\mathbf{1}$ catalyzed reaction. According to the relative cycloadducts formation energy differences, thermodynamic control does not account for the differences experimentally observed between catalyst $\mathbf{1}$ and $\mathbf{5} .^{12}$

However, catalyst $\mathbf{1}$ is sterically more hindered than $\mathbf{5}$, and the possibility that the intermediate iminium is formed very slowly from $\mathbf{1}$, allowing the uncatalyzed background 
reaction to occur, was considered. The net result would be the negligible stereocontrol observed experimentally.

Figure 15 displays the potential-energy profile for the formation of the most stable iminium ions 13(E)-a2 and 14(E)-b2 $\alpha$ (see Figures 9, 10 and 11 ) from protonated amines $\mathbf{1}$ and 5, and $8 s$-cis. These data indicate that formation of $\mathbf{1 4}(E)$-b2 $\alpha$ iminium ion is thermodynamically more favored than formation of $\mathbf{1 3}(E)$-a 2 by $8.5 \mathrm{kcal} / \mathrm{mol}$ in the gas phase. These results can explain the different behavior observed between catalyst $\mathbf{1}$ and $\mathbf{5}$ in the cycloaddition reaction of cyclopentadiene with $\alpha, \beta$-unsaturated ketones. Iminium ions derived from chiral amine $\mathbf{1}$ and 4-hexen-3-one are formed slowly or not at all and, only the uncatalyzed background reaction is observed (48 hours, 20\% yield, 7:1 endo:exo ratio, 0\% ee). ${ }^{12}$ This conclusion is also in agreement with the experimental study reported by Jørgensen et al. on asymmetric addition of nitroalkanes to $\alpha, \beta$-unsaturated enones organocatalyzed by several imidazolines. ${ }^{39}$ Organocatalyst $\mathbf{1}$ gave no conversion after 60 hours.

The different observed stabilities are due to strong steric hindrance produced between the ethyl fragment and the dimethyl groups at position $\mathrm{C} 2$ of the imidazolidinone ring of $\mathbf{1}$. Figure 16 depicts the closest distances between $\mathrm{Ha}$ at the methylene group of the ethyl fragment and substituents at $\mathrm{C} 2$ of the imidazolidinone moiety. Iminium intermediate $13(E)$ a2 presents a Ha- $\mathrm{Ha}^{\prime}$ distance of $1.93 \AA$ and a Ha-Ha" distance of $2.05 \AA$. Ha- $\mathrm{H} 2=2.22 \AA$ was the closest distance found in compound $\mathbf{1 4}(\boldsymbol{E})$-b2 $\alpha$ between the methylene group and the imidazolininone ring substituents.

\title{
Conclusions
}

DFT calculations have demonstrated that secondary amines decrease the activation energies of the Diels-Alder reactions of cyclopentadiene with $\alpha, \beta$-usaturated aldehydes and ketones by 13 and $11 \mathrm{kcal} / \mathrm{mol}$, respectively. The formation of the iminium complex produces a much more reactive dienophile. Although a number of different conformers of iminium intermediates and transition states are located, there is a preference for attack in a sterically unencumbered fashion that leads to a family of preferred transition structures and high stereoselectivity.

The different reactivities observed for imidazolidinone catalysts $\mathbf{1 - 5}$, in the [4+2] cycloaddition reactions of 4-hexen-3-one and cyclopentadiene have been explored. Chiral amines $\mathbf{1}$ and $\mathbf{2}$ form the corresponding iminium intermediates reluctantly with ketone $\mathbf{8}$ due to strong steric hindrance between the ethyl group and substituents at position $\mathrm{C} 2$ of the imidazolidinone ring. ${ }^{41}$ When reactions are performed in the presence of $\mathbf{1}$ and $\mathbf{2}$, only the uncatalyzed background reaction is observed (48 hours, 20\% yield, 7:1 endo:exo ratio, 0\% ee). ${ }^{12}$

\section{Supplementary Material}

Refer to Web version on PubMed Central for supplementary material.

\section{Acknowledgments}

\begin{abstract}
We are grateful to the National Institute of General Medical Sciences, National Institutes of Health, for financial support. This research was facilitated through the Partnerships for Advanced Computational Infrastructure (PACI) through the support of the National Science Foundation. The computations were performed on the National Science Foundation Terascale Computing System at the Pittsburgh Supercomputing Center (PSC) and on the UCLA Academic Technology Services (ATS) Hoffman Beowulf cluster. Ruth Gordillo thanks the Ministerio de Educación, Cultura y Deporte-Spain for a postdoctoral fellowship. We thank Professor David MacMillan and his research group, and Dr. Yu Takano for helpful discussions and suggestions.
\end{abstract}




\section{References}

1. Reviews on enantioselective organocatalysis: a) Dalko PL, Moisan L. Angew Chem Int Ed. 2001; 40:3726-3748.b) Dalko PI, Moisan L. Angew Chem Int Ed. 2004; 43:5138-5175.c) Houk KN, List B. Asymmetric Organocatalysis. Acc Chem Res. 2004; 37:487.

2. Ahrendt KA, Borths CJ, MacMillan DWC. J Am Chem Soc. 2000; 122:4243-4244.

3. Jen WS, Wiener JJM, MacMillan DWC. J Am Chem Soc. 2000; 122:9874-9875.

4. Paras NA, MacMillan DWC. J Am Chem Soc. 2001; 123:4370-4371. [PubMed: 11457218]

5. Brochu MP, Brown SP, MacMillan DWC. J Am Chem Soc. 2004; 126:4108-4109. [PubMed: 15053591]

6. Austin JF, MacMillan DWC. J Am Chem Soc. 2002; 124:1172-1173. [PubMed: 11841277]

7. Paras NA, MacMillan DWC. J Am Chem Soc. 2002; 124:7894-7895. [PubMed: 12095321]

8. Brown SP, Goodwin NC, MacMillan DWC. J Am Chem Soc. 2003; 125:1192-1194. [PubMed: 12553821]

9. Austin JF, Kim SG, Sinz CJ, Xiao WG, MacMillan DWC. Proc Natl Acad Sci USA. 2004; 101:5482-5487. [PubMed: 15067109]

10. Mangion IK, Northrup AB, MacMillan DWC. Angew Chem Int Ed. 2004; 43:6722-6724.

11. (a) Yang JW, Hechavarría-Fonseca MT, List B. Angew Chem Int Ed. 2004; 43:6660-6662.(b) Yang JW, Hechavarría-Fonseca MT, Vignola N, List B. Angew Chem Int Ed. 2004; 44:108-110.

12. Northrup AB, MacMillan DWC. J Am Chem Soc. 2002; 124:2458-2460. [PubMed: 11890793]

13. Molecular mechanics Monte Carlo conformational search with MM3 force field; Macromodel V6.5.

14. (a) Becke AD. J Chem Phys. 1993; 98:1372-1377.(b) Becke AD. J Chem Phys. 1993; 98:56485652.(c) Lee C, Yang W, Parr RG. Phys Rev B. 1988; 37:785-789.(d) Ditchfield R, Hehre WJ, Pople JA. J Chem Phys. 1971; 54:724-728.(e) Hehre WJ, Ditchfield R, Pople JA. J Chem Phys. 1972; 56:2257-2261.(f) Hariharan PC, Pople JA. Theor Chim Acta. 1973; 28:213-222.

15. (a) Bahmanyar S, Houk KN. J Am Chem Soc. 2001; 123:11273-11283. [PubMed: 11697970] (b) Hoang L, Bahmanyar S, Houk KN, List B. J Am Chem Soc. 2003; 125:16-17. [PubMed: 12515489] (c) Bahmanyar S, Houk KN, Martin HJ, List B. J Am Chem Soc. 2003; 125:24752479. [PubMed: 12603135] (d) Bahmanyar S, Houk KN. Org Lett. 2003; 5:1249-1251. [PubMed: 12688731] (e) Wayner G, Houk KN, Sun YK. J Am Chem Soc. 2004; 126:199-203. [PubMed: 14709085] (f) Alleman C, Gordillo R, Clemente FR, Cheong PHY, Houk KN. Acc Chem Res. 2004; 37:558-569. [PubMed: 15311955]

16. Gordillo R, Carter J, Houk KN. Adv Synth Catal. 2004; 346:1175-1185.

17. Dudding T, Houk KN. Proc Natl Acad Sci USA. 2004; 101:5770-5775. [PubMed: 15079058]

18. Frisch, MJ., et al. Gaussian 98, revision A.6. Gaussian, Inc; Pittsburgh, PA: 1998.

19. Scott AP, Radom L. J Phys Chem. 1996; 100:16502-16513.

20. (a) Barone V, Cossi M. J Phys Chem A. 1998; 102:1995-2001.(b) Barone B, Cossi M, Tomasi J. J Comput Chem. 1998; 19:404-417.

21. Frisch, MJ., et al. Gaussian 03, revision B. 04. Gaussian, Inc; Pittsburgh, PA: 2003.

22. Takano Y, Houk KN. J Chem Theory Comput. 2005; 1:70-77.

23. Fu YS, Tsai SC, Huang CH, Yen SY, Hu WP, Yu SJ. J Org Chem. 2003; 68:3068-3077. [PubMed: 12688774]

24. Breslow R, Guo T. J Am Chem Soc. 1998; 110:5613-5617.

25. Breslow R, Maitra U, Rideout D. Tetrahedron Letters. 1983; 24:1901-1904.

26. Kobuke Y, Fueno T, Furukawa J. J Am Chem Soc. 1970; 92:6548-6553.

27. Mellor JM, Webb CF. J Chem Soc, Perkin Trans 2. 1974:17-22.

28. Blokzijil W, Blandamer MJ, Engberts JBFN. J Am Chem Soc. 1991; 113:4241-4246.

29. Kumar A, Phalgune U, Pawar SS. J Phys Org Chem. 2000; 13:555-557.

30. Baldwin JE, Herchen SR, Schulz G. J Am Chem Soc. 1980; 102:7816-7817.

31. Meijer A, Otto S, Engberts JBFN. J Org Chem. 1998; 63:8989-8994.

32. Breneman CM, Wiberg KB. J Comp Chem. 1990; 11:361-373. 
33. Washington I, Houk KN. Angew Chem Int Ed. 2001; 40:4485-4487.

34. García Ruano JL, Fraile A, González G, Martín MR, Clemente FR, Gordillo R. J Org Chem. 2003; 68:6522-6534. [PubMed: 12919012]

35. Nishio M. Tetrahedron. 2005; 61:6923-6950.

36. a) Domingo LR, Aurell MJ, Pérez P, Contreras R. J Org Chem. 2003; 68:3884-3890. [PubMed: 12737567] b) Domingo LR. Tetrahedron. 2002; 58:3765-3774.c) Domingo LR. J Org Chem. 2001; 66:3211-3214. [PubMed: 11325291] d) Evanseck JD, Kong S. J Am Chem Soc. 2000; 122:10418-10427.

37. Schaftenaar G, Noordik JH. Vibrational mode visualization was performed using the MOLDEN program: Molden: a pre- and post-processing program for molecular and electronic structures. $\mathrm{J}$ Comput-Aided Mol Design. 2000; 14:123-124.

38. Zora M. J Mol Struct (THEOCHEM). 2002; 619:121-133.

39. Kozlowisky MC, Panda M. J Org Chem. 2003; 68:2061-2076. [PubMed: 12636364]

40. Distances ( 3.7 and $3.8 \AA$ ) are in good agreement with previous theoretical studies on benzenemethane complexes: Tsuzuki S, Honda K, Uchimaru T, Mikami K, Tanabe K. J Am Chem Soc. $2000 ; 122: 3746-3753$.

41. Halland N, Hazell RG, Jørgensen KA. J Org Chem. 2002; 67:8331-8338. [PubMed: 12444609] 


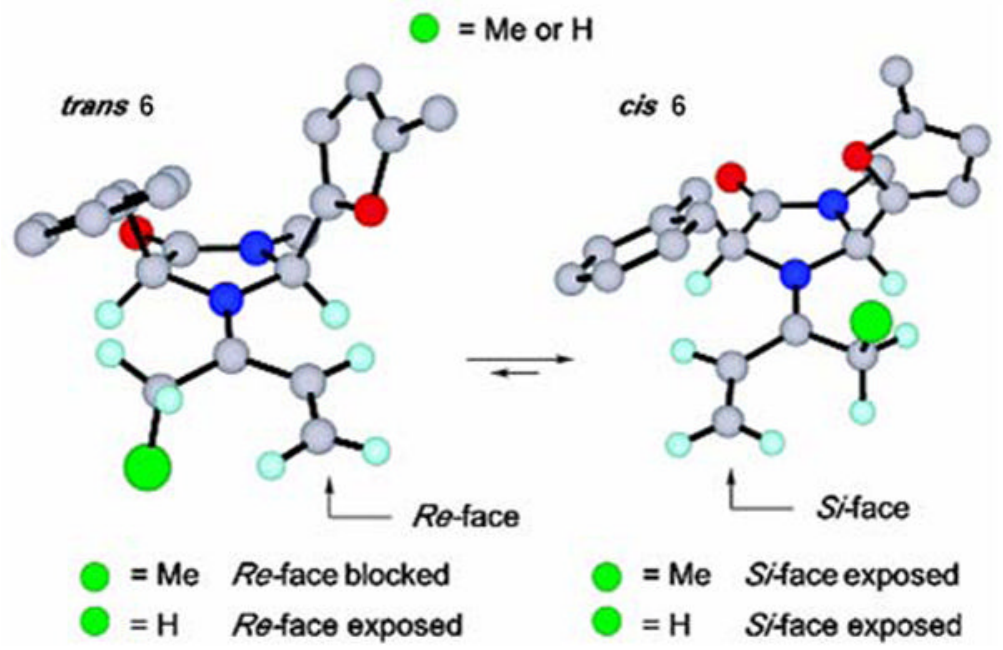

Figure 1.

Computed MM conformations of iminium ion $\mathbf{6}$, derived from amine $\mathbf{5}$ and 4-hexen-3-one. ${ }^{13}$ Reprinted with permission from J. Am. Chem. Soc. 2002, 124, 2458-2460. Copyright 2002 American Chemical Society. 


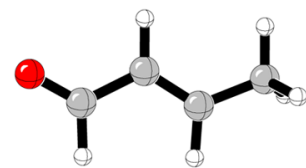

7 s-trans $(0.0)$

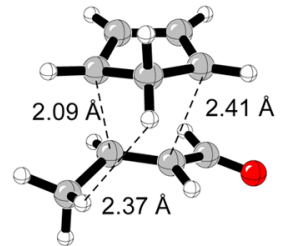

TS7 s-trans-endo (2.6)

$\Delta \mathrm{E}^{\ddagger}=23.3$

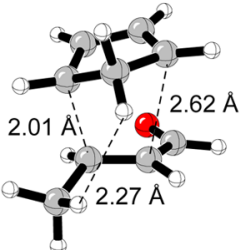

TS7 s-cis-endo (0.7) $\Delta \mathrm{E}^{\ddagger}=21.5$

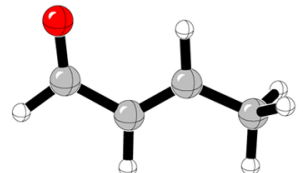

7 s-cis (1.4)

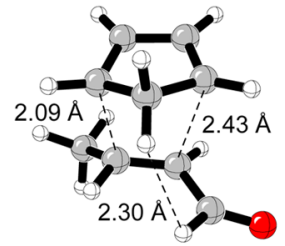

TS7 s-trans-exo (2.1) $\Delta \mathrm{E}^{\ddagger}=22.8$

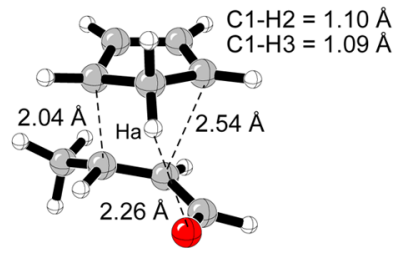

TS7 s-cis-exo (0.0) $\Delta \mathrm{E}^{\ddagger}=20.7$

Figure 2.

$S$-cis- and $s$-trans- $(E)$-crotonaldehyde conformers and calculated transition structures for Diels-Alder reactions with cyclopentadiene. Relevant distances are in $\AA$. Relative energies for the gas phase and activation energies (kcal/mol) are shown. 


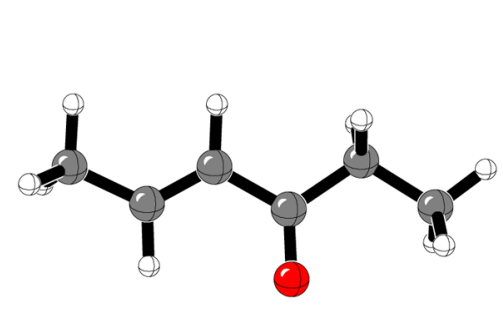

$8 \mathrm{~s}$-cis

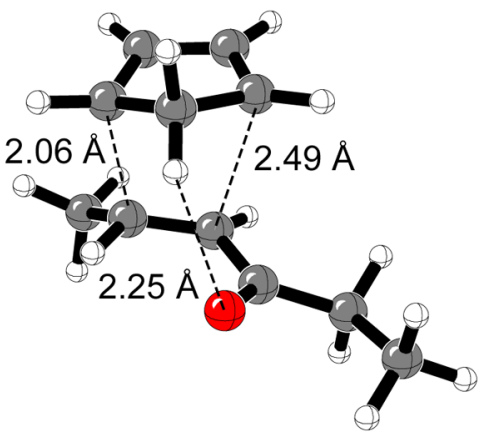

TS8 s-cis-exo

$\Delta \mathrm{E}^{\ddagger}=20.9$

Figure 3.

Most stable 4-hexen-3-one conformer and transition structure for Diels-Alder reactions with cyclopentadiene. Relevant distances are in $\AA$. Activation energy (kcal/mol) is shown. 


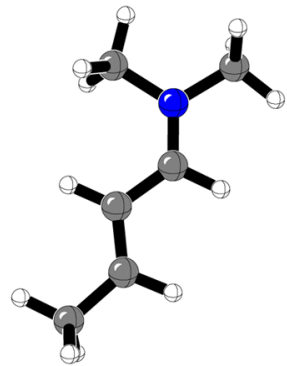

9 s-trans $(0.0)$

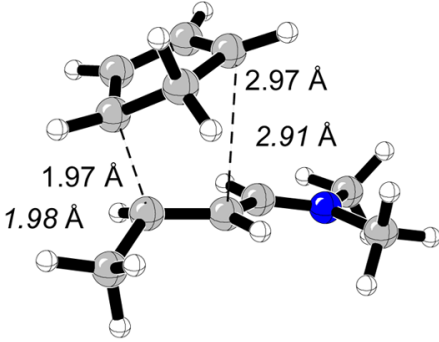

TS9 s-trans-endo (0.5) [0.7] [0.6] TS9 s-trans-exo (0.0) [0.0] [0.0] $\Delta \mathrm{E}^{\ddagger}=7.3$

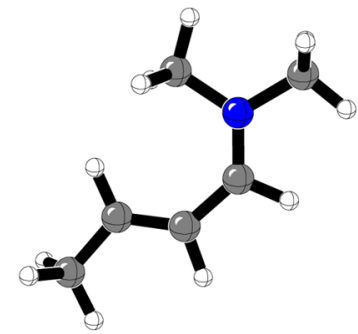

9 s-cis $(6.4)$

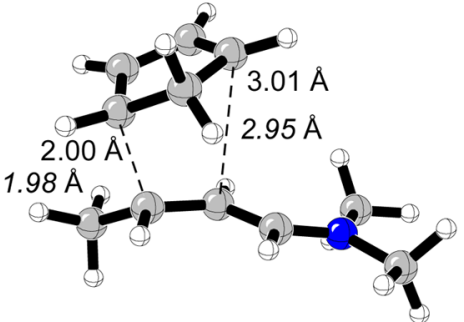

$\Delta \mathrm{E}^{\ddagger}=6.9$

Figure 4.

Calculated $s$-cis and $s$-trans- $N$-2-butenylidene- $N$-methylmethanaminium cation $(\mathbf{9})$ and transition structures for Diels-Alder reactions with cyclopentadiene. Relevant distances are in $\AA$. Relative energies for the gas phase (or water in brackets, full optimization in water in italic) and activation energies $(\mathrm{kcal} / \mathrm{mol})$ are shown. 


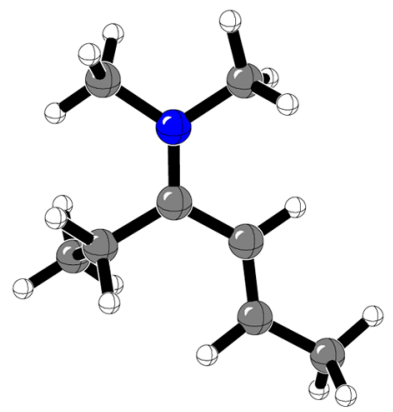

10 s-trans $(0.0)$

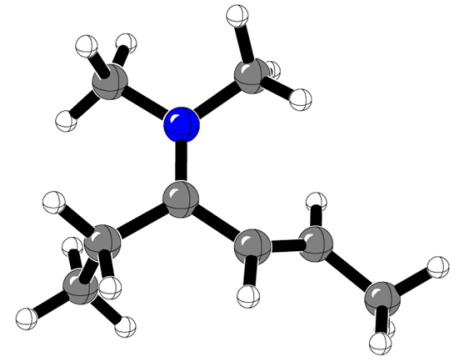

10 s-cis2 (2.9)

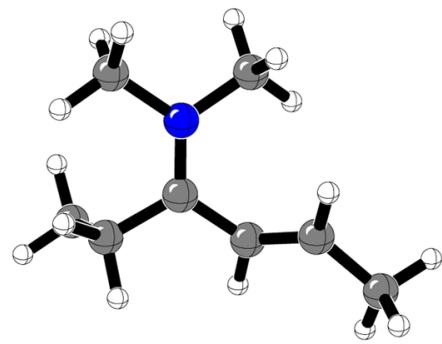

$10 \mathrm{~s}-\operatorname{cis} 1(3.5)$

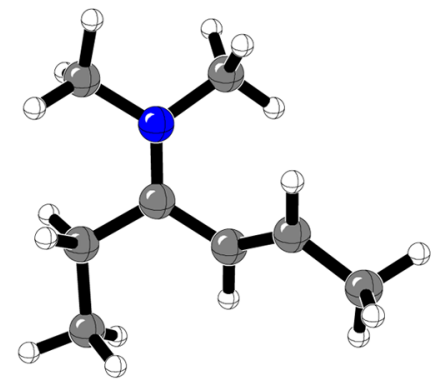

10 s-cis3 (3.8)

Figure 5.

Calculated $s$-cis and $s$-trans $N$-2-butenylidene- $N$-1-ethyl- $N$-methylmethanaminium cation (10). Relative energy differences $(\mathrm{kcal} / \mathrm{mol})$ are shown. 


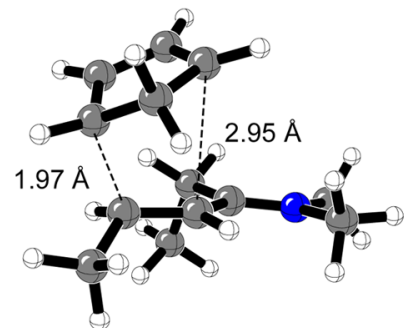

TS10a s-trans-endo $(0.0)[0.0]$ $\Delta \mathrm{E}^{\ddagger}=9.8$

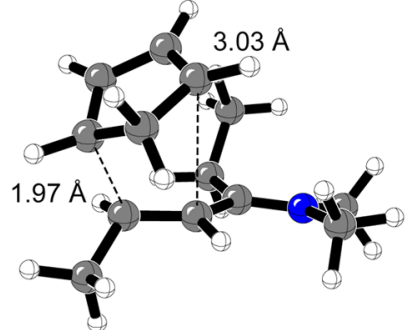

TS10b s-trans-endo (2.6) [2.4] $\Delta \mathrm{E}^{\ddagger}=12.4$

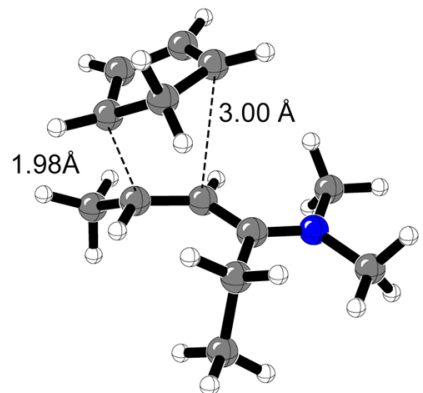

TS10a s-trans-exo (0.6) [0.8] $\Delta \mathrm{E}^{\ddagger}=10.4$

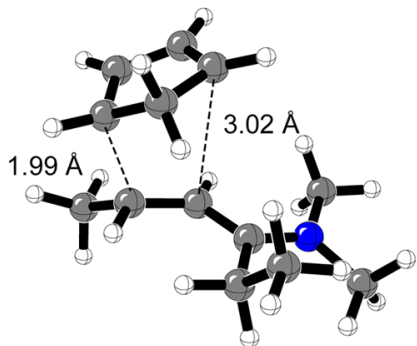

TS10b s-trans-exo (2.2) [2.1] $\Delta \mathrm{E}^{\ddagger}=12.0$

Figure 6.

Calculated transition structures for the Diels-Alder reactions of $\mathbf{1 0} s$-trans with cyclopentadiene. Relative distances are in $\AA$. Relative energies for the gas phase (or water, in brackets) and activation energies $(\mathrm{kcal} / \mathrm{mol})$ are shown. 


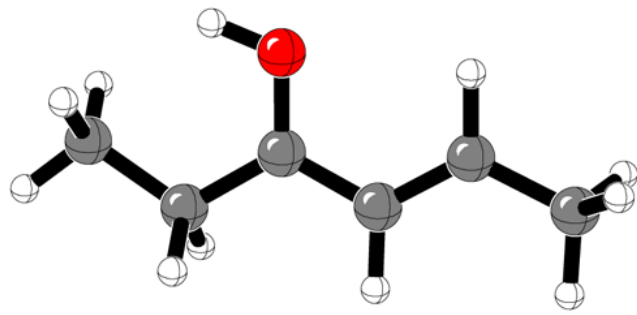

$11 \mathrm{~s}$-cis

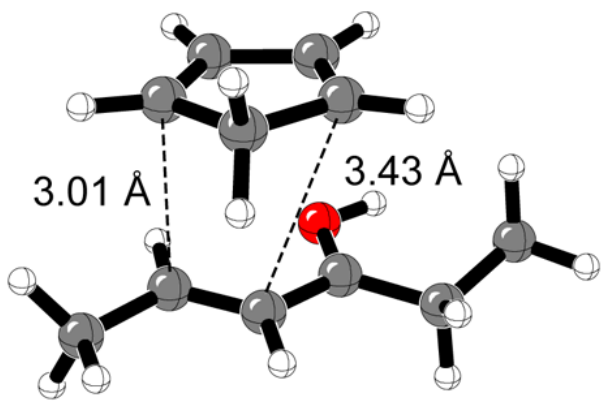

$$
\begin{aligned}
& \text { complex } 11 \text { s-cis-endo } \\
& \Delta E_{f}=-5.9
\end{aligned}
$$

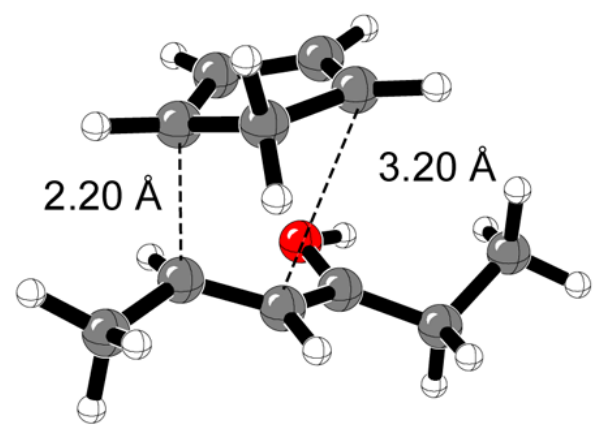

TS11 s-cis-endo

$$
\begin{aligned}
& \Delta \mathrm{E}^{\ddagger} \text { (separated reactants) }=-3.0 \\
& \Delta \mathrm{E}^{\ddagger}=2.9
\end{aligned}
$$

Figure 7.

Most stable protonated $s$-cis 4-hexen-3-one conformer, Diels-Alder transition structure, and ion-molecule complex. Relevant distances are in $\AA$. Activation and formation energies (kcal/ mol) are shown. 


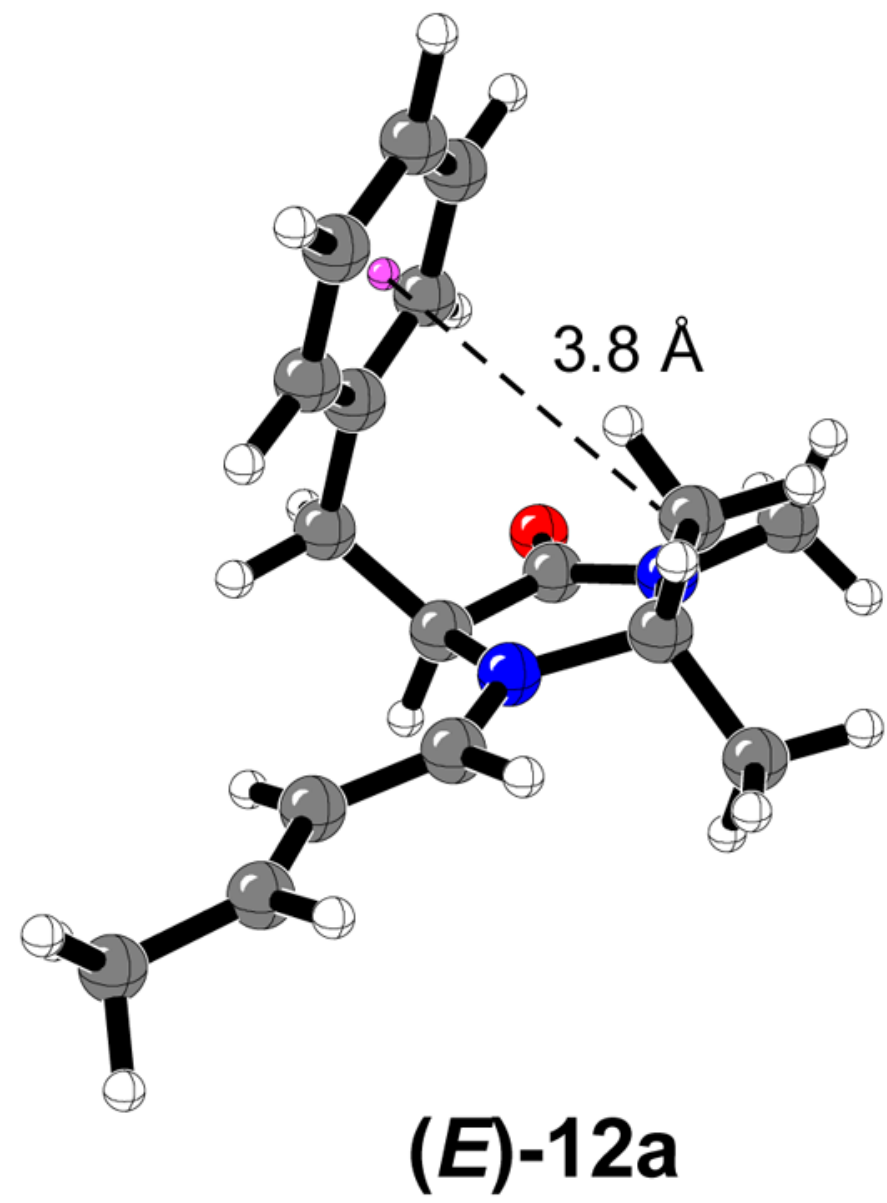

Figure 8.

Most stable iminium ion conformer formed from catalyst $\mathbf{1}$ and $(E)$-crotonaldehyde. ${ }^{16}$ 


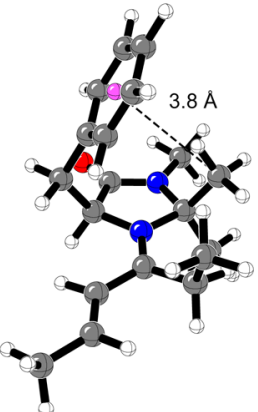

$13(E)-\mathrm{a} 1(0.1)$

$24 \%$

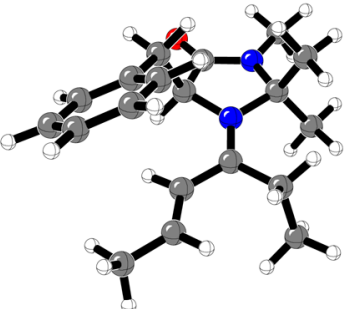

13(E)-b2 (2.0)

$1 \%$

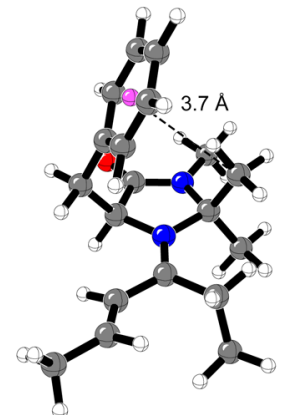

$13(E)-\mathrm{a} 2(0.0)$

$28 \%$

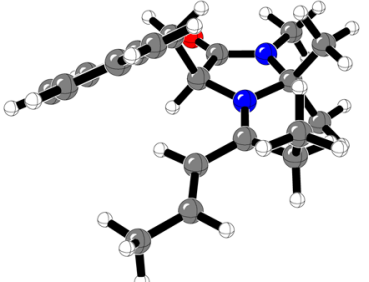

13(E)-b1 (2.1)

$1 \%$

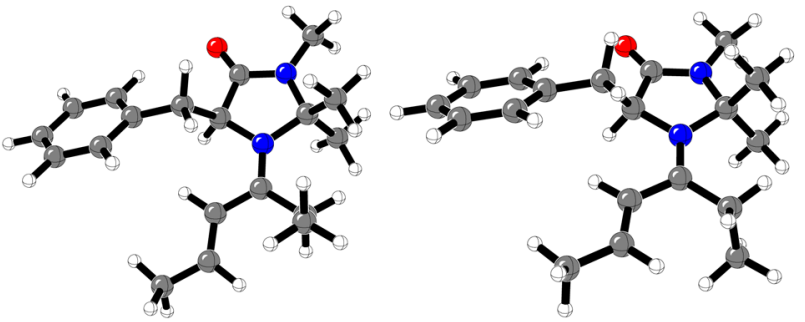

$13(E)-\mathrm{c} 2(1.1)$

Figure 9.

Optimized structures, relative energy differences ( $\mathrm{kcal} / \mathrm{mol})$, calculated respect to the lowest energy isomer $13(E)-\mathbf{a} 2$, and percentage of each structure in the gas phase at $0{ }^{\circ} \mathrm{C}$ for the $\mathbf{1 3}(\boldsymbol{E})$-iminium complexes formed from chiral imidazolidinone $\mathbf{1}$ and 4-hexen-3-one. 


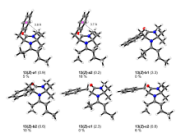

Figure 10.

Optimized structures, relative energy differences $(\mathrm{kcal} / \mathrm{mol})$, calculated respect to the lowest energy isomer $\mathbf{1 3}(\boldsymbol{E})$-a2 (Figure 9), and percentage of each structure in the gas phase at $0{ }^{\circ} \mathrm{C}$ for the 13(Z)-iminium complexes formed from chiral imidazolidinone $\mathbf{1}$ and 4-hexen-3-one. 


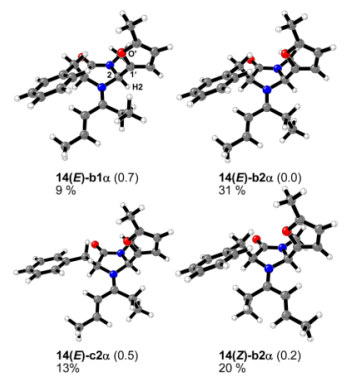

Figure 11.

Most stable calculated structures, relative energy differences ( $\mathrm{kcal} / \mathrm{mol})$, calculated respect to the lowest energy isomer $\mathbf{1 4}(\boldsymbol{E})-\mathbf{b 2} \alpha$, and percentage of each structure in the gas phase at $0{ }^{\circ} \mathrm{C}$ for the 14-iminium complexes formed from $\mathbf{5}$ and 4-hexen-3-one. 


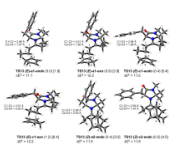

Figure 12.

Most stable calculated transition structures for the Diels-Alder reaction of cyclopentadiene with 4-hexen-3-one catalyzed by chiral imidazolidinone 1 . Relevant distances are in $\AA$. Relative energies for the gas phase (or water, in brackets) and activation energies (kcal/mol) are shown. 

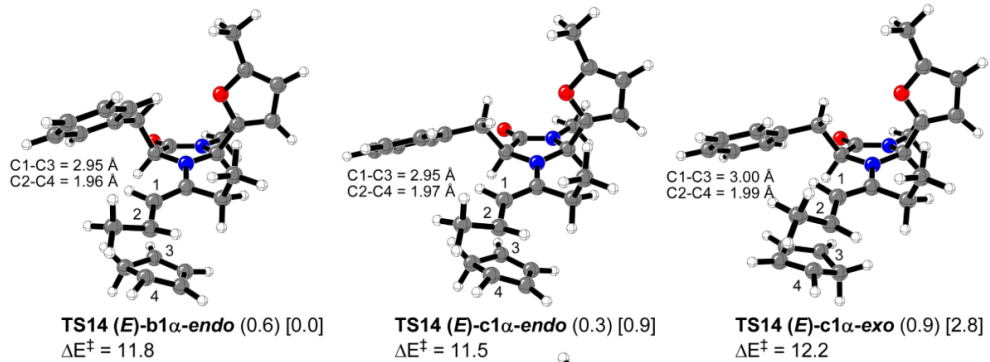

TS14 (E)-b
$\Delta E^{\ddagger}=11.8$

TS14 (E)-c1 $\alpha$-endo (0.3) [0.9]

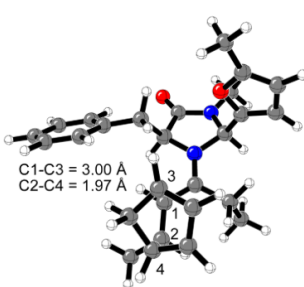

TS14 (E)-c2a-endo (0.8) [2.8]

$\Delta E^{\ddagger}=12.0$

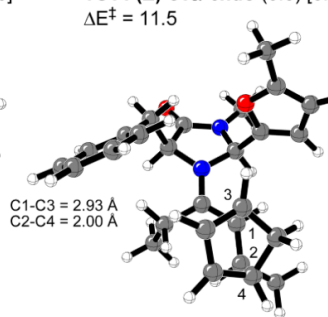

TS14 (Z)-b2a-endo (0.0) [1.9] $\Delta \mathrm{E}^{\ddagger}=11.2$

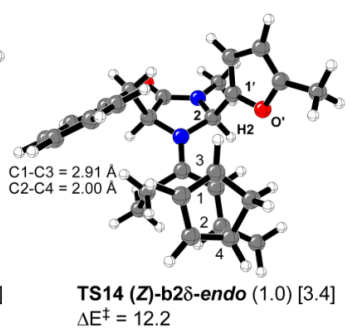

Figure 13.

Most stable calculated transition structures for the Diels-Alder reaction of cyclopentadiene with 4-hexen-3-one catalyzed by chiral imidazolidinone 5. Relevant distances are in $\AA$. Relative energies for the gas phase (or water, in brackets) and activation energies (kcal/mol) are shown. 


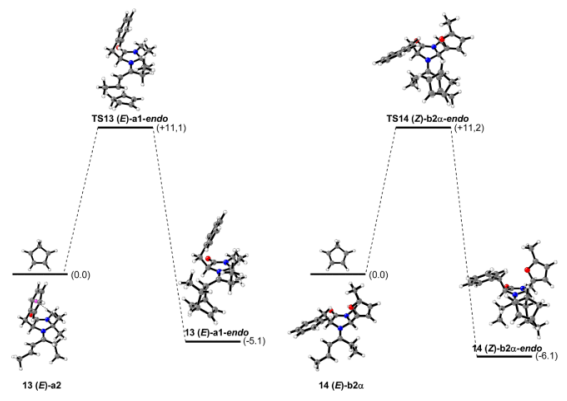

Figure 14.

Potential-energy profile for cycloaddition reactions involving the most stable transition structures in the gas phase TS13 (E)-a1-endo and TS14 (Z)-b2 $\alpha$-endo. 


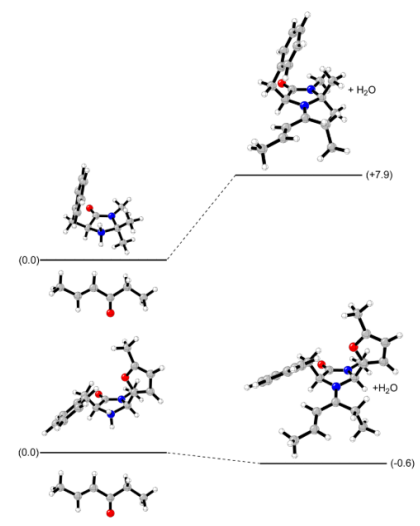

Figure 15.

Computed energies of formation of $\mathbf{1 3}(E)-\mathbf{a} 2$ and $\mathbf{1 4}(E)-\mathbf{b} \mathbf{2} \alpha$ iminium ions from protonated amines $\mathbf{1}$ and $\mathbf{5}$ in the gas phase. 


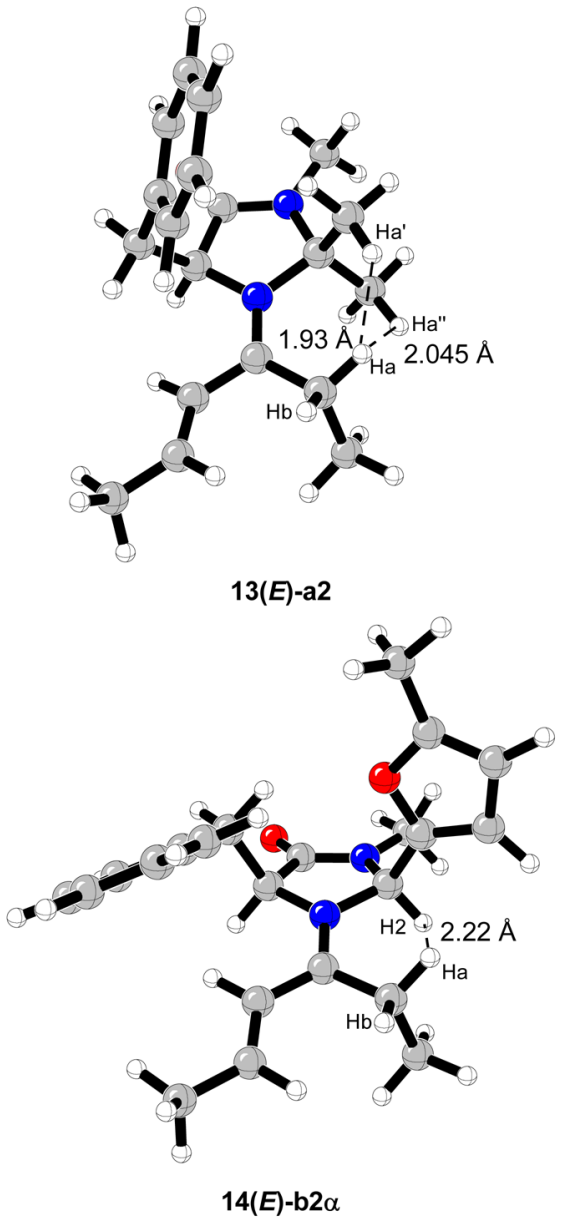

Figure 16.

Most stable calculated $\mathbf{1 3}(E)$-a2 and $\mathbf{1 4}(E)$-b2 $\alpha$ iminium intermediates. Closest distances between methylene group and $\mathrm{C} 2$ imidazolidinone ring substituents are shown $(\AA)$. 


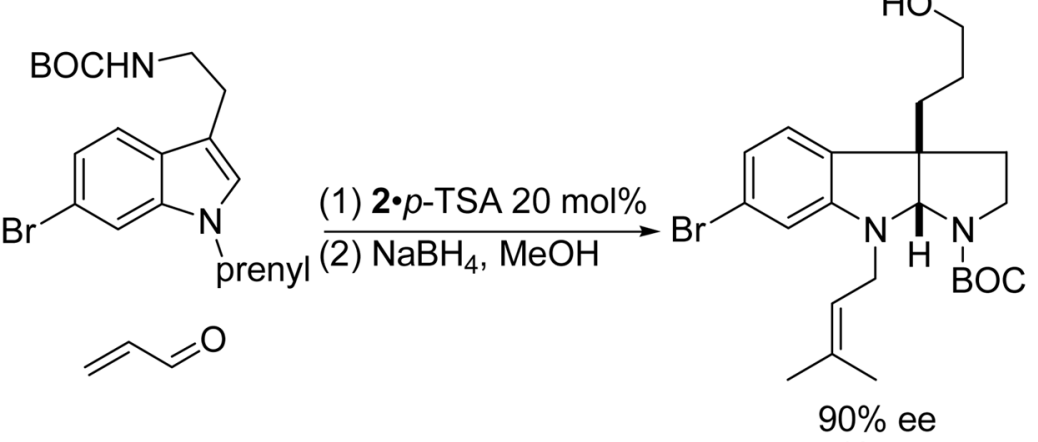

$78 \%$ yield

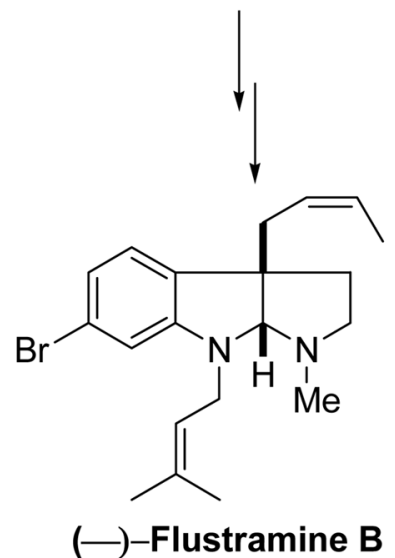

Scheme 1.

Total synthesis of (-)-flustramine B using catalyst $2 .{ }^{9}$ 
<smiles>[R]N[R]N[R]</smiles>

Scheme 2.

Activation of the carbonyl compound by iminium ion formation. 


\section{Table 1}

Calculated relative energy difference and percentage of transition structures TS13 in the gas phase and water at $0{ }^{\circ} \mathrm{C}$.

\begin{tabular}{|c|c|c|c|c|}
\hline \multirow{2}{*}{ Transition Structure } & \multicolumn{2}{|l|}{ Gas phase } & \multicolumn{2}{|l|}{ Water } \\
\hline & Energy Difference (kcal/mol) & Percent & Energy Difference (kcal/mol) & Percent \\
\hline TS13 (E)-a1-endo & 0.0 & 35 & 1.8 & 4 \\
\hline TS13 (E)-a1-exo & 0.9 & 6 & 3.9 & 0 \\
\hline TS13 (E)-a2-endo & 3.9 & 0 & 5.5 & 0 \\
\hline $\operatorname{TS} 13(E)-\mathbf{a} 2-$ exo & 4.6 & 0 & 6.2 & 0 \\
\hline TS13 (E)-c1-endo & 0.4 & 16 & 5.4 & 0 \\
\hline TS13 (E)-c1-exo & 1.2 & 4 & 6.4 & 0 \\
\hline TS13 (E)-c2-endo & 3.1 & 0 & 6.6 & 0 \\
\hline TS13 (E)-c2-exo & 5.5 & 0 & 7.8 & 5 \\
\hline TS13 (Z)-a1-endo & 3.9 & 0 & 4.4 & 0 \\
\hline TS13 (Z)-a1-exo & 5.4 & 0 & 5.6 & 0 \\
\hline TS13 (Z)-a2-endo & 0.4 & 18 & 0 & 96 \\
\hline TS13 (Z)-a2-exo & 1.4 & 3 & 5.6 & 0 \\
\hline TS13 (Z)-b2-endo & 1.4 & 3 & 6.3 & 0 \\
\hline TS13 (Z)-b2-exo & 2.2 & 1 & 6.9 & 0 \\
\hline TS13 (Z)-c2-endo & 0.5 & 13 & 4.5 & 0 \\
\hline $\operatorname{TS13}(Z)$-c2-exo & 1.7 & 2 & 5.7 & 0 \\
\hline
\end{tabular}




\section{Table 2}

Calculated relative energy difference, electronic activation energies, and percentage of transition structures TS14 in the gas phase at $0{ }^{\circ} \mathrm{C}$.

\begin{tabular}{|c|c|c|c|c|}
\hline \multirow{2}{*}{ Transition Structure } & \multicolumn{2}{|l|}{ Gas phase } & \multicolumn{2}{|l|}{ Water } \\
\hline & Energy Difference (kcal/mol) & Percent & Energy Difference (kcal/mol) & Percent \\
\hline TS14 (E)-b1 $\alpha-e n d o$ & 0.6 & 11 & 0.0 & 79 \\
\hline 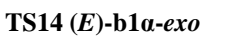 & 1.4 & 3 & 2.1 & 2 \\
\hline TS14 (E)-b2 $\alpha-e n d o$ & 1.4 & 3 & 5.0 & 0 \\
\hline TS14 (E)-b2a-exo & 4.3 & 0 & 7.7 & 0 \\
\hline TS14 (E)-b2 & 2.2 & 1 & 5.9 & 0 \\
\hline TS14 (E)-b28-exo & 4.8 & 0 & 11.1 & 0 \\
\hline TS14 (E)-c1a-endo & 0.3 & 22 & 0.9 & 16 \\
\hline TS14 (E)-c1a-exo & 0.9 & 6 & 2.8 & 0 \\
\hline TS14 (E)-c2a-endo & 0.8 & 8 & 2.8 & 0 \\
\hline TS14 (E)-c2a-exo & 2.7 & 0 & 4.6 & 0 \\
\hline TS14 (E)-c2 $\delta$-endo & 1.8 & 1 & 4.2 & 0 \\
\hline TS14 (E)-c28-exo & 3.4 & 0 & 5.4 & 0 \\
\hline TS14 (Z)-b2a-endo & 0.0 & 35 & 1.9 & 2 \\
\hline TS14 (Z)-b2a-exo & 1.1 & 5 & 2.6 & 1 \\
\hline TS14 (E)-b28-endo & 1.0 & 6 & 3.4 & 0 \\
\hline TS14 (E)-b2 & 2.8 & 0 & 4.2 & 0 \\
\hline
\end{tabular}

